\title{
Who's minding the kids? An economic comparison of sole and joint custody*
}

\author{
Linda Welling** and Marci Bearance*** \\ **Department of Economics, University of Victoria \\ PO Box 1700, Victoria, B.C. Canada V8W 2Y2 \\ ***Ministry of Multiculturalism and Immigration \\ Government of British Columbia, Canada
}

This version July 2001

\begin{abstract}
We examine the allocation of spending by divorced parents on both private goods and goods which they share with their child. Sole and joint custody arrangements differ in the pattern of shared goods. Parents play a non-cooperative game. We compute and compare the outcomes under sole and joint custody, and examine the effects of income redistribution.

JEL Classification: D19, H41, H22

*This paper was presented at the 1999 IAFFE annual conference, in a CWEN session at the 1998 annual meetings of the Canadian Economics Association, and the 1998

Canadian Law and Economics Association. Comments by Peter Burton, John Hoddinott, Robert Willis, and an anonymous referee improved our understanding of the topic and helped refocus the paper; they are not responsible for any remaining errors. Welling's research was funded in part by the Social Sciences and Humanities Research Council of Canada.
\end{abstract}

Correspondence should be addressed to Linda Welling, at welling@uvvm.uvic.ca, or the address above, or at (250) 721-8546 or FAX (250) 721-6214 


\section{Introduction}

The distribution of resources within a family is receiving increased attention from both theoretical and policy analysts. Traditional economic analysis assumed that households make consistent economic choices, without worrying about the decisionmaking process. With both the media and politicians focusing on the advantages and disadvantages to children of being raised in various family structures, informed policy analysis must be based on models which allow for disagreements within a family.

When they appear in economic models, children are typically consuming but not purchasing household members. ${ }^{1}$ A child makes no independent decisions, but is a household public good; each parent contributes to the well being of, and derives psychological benefits from, the child. Recent work has suggested the need for more complicated modeling. Phipps and Burton (1992, 1995), and Lundberg, Pollak and Wales (1997), provide evidence that, within marriage, mothers and fathers choose expenditures on children differently. These differences frequently become a source of explicit conflict after a marriage has dissolved, and the parents live apart.

In this paper, we focus on expenditures after divorce. In particular, we are interested in understanding and comparing the effects on children and their parents of two custodial arrangements: sole custody and joint custody. Traditionally, mothers have received sole custody of children after separation or divorce, in recent years more and

${ }^{1}$ With the notable exception of Becker's "rotten kid", minor children are typically denied any active economic role. This paper continues that trend. 
more parents are agreeing on some form of joint custody. The notion of custody has some inherent ambiguity, since it may apply to legal custody, physical custody, or both. Here we focus on physical custody, and sole and joint custody are differentiated by the amount of time the child spends with each parent, as well as the financial transfers.

Many separating couples do not negotiate or file legal separation agreements; this suggests that post separation cooperation on child expenditures is possible. On the other hand, the existence of legislation governing child support payments suggests that cooperation is not common. The economic literature on child support typically assumes that spending on the child(ren) is determined non-cooperatively. This paper assumes that negotiated child support transfers have been made, and subsequent spending is determined non-cooperatively.

The efficiency of expenditures on children under sole custody is examined in Weiss and Willis (1985), and Del Boca and Flinn (1995). They point out that although the non-custodial parent can transfer resources to the custodial parent, he or she cannot control the latter's expenditures. Since both parents continue to care for the children, but the custodial parent does not consider the welfare of the other parent when determining priorities, spending on the child is typically inefficient.

Brinig and Buckley (1997) argue that joint custody provides many potential benefits to children. After a divorce, children are more likely to have two parents who are actively involved in raising them. With single parent custody, not only does a child see less of the non-custodial parent, but he or she may also see less of the custodial parent who may be faced with increased responsibilities and fewer financial resources. Joint 
custody may also serve to eliminate agency problems, making compliance with support agreements less of an issue. Finally, anticipation of joint custody may change the child care arrangements within the household before divorce, with fathers allowing themselves to bond more closely with their children if it is likely that they will retain partial custody.

In this paper, we introduce a new model of joint and sole custody. A complete story would incorporate marriage and divorce, ${ }^{2}$ and future as well as current effects on children of any transition. Here we focus on discretionary resource allocation after parents separate. We take as given the discretionary incomes of each parent, assuming that any court-ordered support payments from the non-custodial to the custodial parent have been made. We derive the spending patterns of each parent on themselves and their minor child. ${ }^{3}$ Parents make all decisions, purchasing goods for themselves and the child. We assume neither parent can control the spending of the other, in either custodial regime, and solve for the Nash equilibrium consumption.

${ }^{2}$ We make no distinction between separation and divorce. There is some evidence that financial arrangements differ between these states; this is an area of continuing research for the Child Support Team of the Department of Justice, Canada.

${ }^{3}$ More than one child would complicate the analysis unduly at this stage. 
In common with most other models, we assume both parents are altruistic towards the child, while the child is selfish. ${ }^{4}$ Thus spending on the child is a public good for the parents. We broaden previous analyses by explicitly considering two types of goods: private goods, consumed by each of the three individuals in our model, and household public goods. The latter are shared by the child and one of the parents.

The distinction between sole and joint custody involves the public goods: the custodial regime determines the publicness of household goods. Under sole custody, the child shares certain goods with the custodial parent, while the non-custodial parent consumes different household goods. The most obvious of these is housing. When a child lives with one parent, that parent must provide space appropriate for both adult and child. This can mean the adult choosing housing based on schools, playgrounds, etc, attributes not necessarily relevant to an adult living alone. The non-custodial parent, on the other hand, need not consider these characteristics directly. Under joint custody, the child shares goods with both parents. In either regime, each parent buys goods that are used solely by the child: clothes, toys, sports and music lessons, etc.

We solve for the Nash equilibria under both joint and sole custody. Clearly, the equilibrium depends on both the preferences of the parents and the incomes available to them, separately and collectively. Our focus in this paper is the constraint imposed on

${ }^{4}$ One notable exception is Aiyigari et al (1997), where non-custodial fathers have no interest in the welfare of their children. Other possible configurations are presented in Lazear and Michael (1988). 
spending and utilities by the division of family income under the two custodial arrangements. We show that under sole custody, the child's consumption - and, therefore, utility - is invariant to redistributions of family income, within a given range. This implies that small changes in child support payments, which shift discretionary income from the custodial to the non-custodial parent, can have no affect on the child. ${ }^{5}$ Outside of that range, redistribution of income between the mother and the father will alter spending on the child. Similar results hold under joint custody, albeit for different distributions of income. Since changes in outside income will alter spending, the welfare effect of a change in the income of either parent may depend upon the source of that income. Given the outcomes under joint and sole custody individually, we show that the child can be better off under sole custody.

The results of this model will feed back into the initial determination of custody and support. We see that as the first stage in a two-stage game; the analysis in this paper covers the second stage. In the first stage, parents determine who will have custody of the child - either by themselves, or with the "help" of a third party in the form of the legal system or a mediator. The level and frequency of child support payments are also determined at this time. In the second stage, given the custodial regime and after having complied with any child support agreement, the parents independently and simultaneously choose their spending on goods for themselves and the child. The custodial (non-custodial) parent's resources in the second stage will be their own private

${ }^{5}$ Del Boca and Flinn (1994: 748) derive a similar result with no goods shared between child and custodial parent. Our work broadens this result, and extends it to joint custody. 
income, plus (minus) any child support transfer. Monitoring a former marriage partner's expenditures is not feasible, but each knows the other's preferences sufficiently well to enable them to predict their spending patterns.

We describe our assumptions on goods and preferences in the first section of this paper. In the second section, we define sole and joint custody, and solve for the Nash equilibrium in each regime. The third section contains a discussion of the comparison between the two. Section 4 uses the model to some of the debates over the recent change in the Canadian taxation of support payments. The final section presents some planned extensions.

\section{Defining goods and preferences}

Each individual consumes two goods. The custodial regime determines which parent's household goods are shared.

\subsection{Goods}

Each parent has two consumption goods: a private good, $x_{i}, i=m, f$, consumed by the mother (m) or the father (f), and a second good $z_{i}, i=m, f$, shared with anyone living with the purchaser - think of the second good as housing. The child consumes a private good, $x_{c}$, and shares the housing provided by the custodial parent(s). Both parents can purchase private consumption goods for the child; the child's total consumption is simply the sum of the amounts provided by the parents. Under sole custody, the child consumes the housing provided by the custodial parent. Under joint 
custody, the child shares housing with both parents. Since it is difficult to imagine an individual "consuming" two living spaces to the same degree as does the person who inhabits either full time, the child's housing consumption, $z_{c}=f \mathbf{G}_{m}, z_{f} \mid$, is something other than the sum of the amounts consumed by the parents. ${ }^{6}$

\subsection{General preferences}

Each individual has a private utility function defined over their own consumption of housing and their private good: $U_{j}\left(x_{j}, z_{j}\right), j=m, f, c$; these preferences are assumed to be independent of the custodial arrangements per se. Further, each parent cares for the child, but not the former partner; thus each has an interdependent utility function of the form $V_{j}\left(x_{j}, z_{j}, U_{c}\left(x_{c}, z_{c}\right)\right), j=m, f$. We assume altruism is one-sided, so the child is strictly selfish. Since the child's consumption of housing, $z_{c}$, depends on the custody arrangement, the functional dependence of each parent's overall utility on the choice variables will depend on the custodial regime.

\subsection{Children as public goods:}

\footnotetext{
${ }^{6}$ The functional form chosen to represent the child's consumption of housing will be a crucial determinant of the results of the exercise in this paper. This issue is addressed in more detail below.
} 
As in Kanbur (1995), the child's utility is a public good to which each parent may contribute. By focusing on a Nash equilibrium in the game between the parents, we are invoking a voluntary contribution game. It is known that, for a single public good, in a Nash equilibrium the level of the public good provided is invariant to income redistribution between contributors. ${ }^{7}$ If, however, income redistribution alters the total income of the contributors, then the level of the public good may change. (See, for instance, Bergstrom et al (1986) and Warr (1983).) In the current framework, these results imply that transfers between parents should not alter the child's utility so long as both parents contribute to that utility both before and after any transfer. For a divorced family with child support transfers, where the child is a standard public good, small changes in the level of child support should not alter the child's utility.

Two features complicate the current contribution game. First, the number of goods to which parents contribute depends on the custodial arrangements: under joint custody there are two simultaneous contribution games, while under sole custody the father (the non-custodial parent) contributes to at most one good. Second, while the child's private good, $x_{c}$, is a standard public good (both mother and father (can)

${ }^{7}$ A Nash equilibrium is defined in terms of the choices made by the individual decisionmakers. Income redistribution will induce decision-makers to alter their choices, hence there are many Nash equilibria, each corresponding to a particular distribution of income. However, so long as the identity of contributors remains unchanged, each Nash equilibrium corresponds to the same aggregate level of the public good - it is this level which is unique. 
contribute, and the amount "consumed" by each is the same), the second good consumed by the child is different. Housing is not a standard public good because of the asymmetry of the parents' consumption. Housing enters the custodial parent's utility function both directly and indirectly. The other parent's contribution (to the child's housing) enters parent i's utility only indirectly. Therefore each parent cares about the distribution of the provision of housing, as well as the total quantity provided. ${ }^{8}$

\section{Allocation of goods under sole and joint custody: interior solution?}

In this section we characterize the Nash equilibrium to the contribution game under each custodial regime. We consider sole custody (by the mother) first, and then joint custody. The general problem facing each parent in each regime is straightforward to describe; following the general problems we focus on a particular functional form to characterize the Nash equilibrium in each regime.

\subsection{The parents' general decision problems}

${ }^{8}$ This is similar in effect to the "warm-glow giving", discussed in Andreoni (1990): one could interpret this as each parent deriving utility from the act of contributing this good to the child.

${ }^{9}$ We assume here that the non-negativity constraints on parents expenditures are not binding, and discuss the consequences of binding constraints in section 3.3. 
Define units of the private goods so that one unit costs one dollar and let $\mathrm{p}$ be the (relative) price of housing. The mother's problem is then to choose the level of her own private consumption, the housing she shares with her child, and the amount she contributes to the child's private good. The mother takes as given her portion of family income (net of support payments) and the spending undertaken by the father. Thus, the mother's problem is

$$
\max _{x_{m}, z_{m}, x_{c m}} V_{m}\left(x_{m}, z_{m}, U_{c}\left(x_{c m}, x_{c f}, z_{c}\left(z_{m}, z_{f}\right)\right)\right)+\lambda_{m}\left[Y_{m}-x_{m}-p z_{m}-x_{c m}\right]
$$

The father's problem is analogous: he takes as given his own income (net of support payments) and the mother's expenditures, and chooses private goods for himself and the child, and his housing:

$$
\max _{x_{f}, z_{f}, x_{c f}} V_{f}\left(x_{f}, z_{f}, U_{c}\left(x_{c m}, x_{c f}, z_{c}\left(z_{m}, z_{f}\right)\right)\right)+\lambda_{f}\left[Y_{f}-x_{f}-p z_{f}-x_{c f}\right]
$$

In the Nash equilibrium, neither parent wishes to change his or her expenditures, given the spending of the other parent.

\subsection{Defining sole custody and joint custody}

Under sole custody, the child lives fulltime with the mother, so $z_{c}=f\left(z_{m}, z_{f}\right)=z_{m}^{s}$. The housing chosen by the mother indirectly affects the father (positively) because he values the child's utility, while the father's housing decision affects only himself.

When parents have joint custody, the child's consumption is more complicated. For a first pass, suppose that under joint custody parents are completely symmetric: each shares housing with the child, as well as contributing independently towards the child's 
private consumption. To ensure a simple closed form solution, we assume that the amount of housing consumed by the child is linear in the sum of the amount provided by the two parents. Any disutility arising from switching between households is incorporated by discounting the amount of housing by a fraction; in particular, we have

$$
z_{c}^{j}=f \boldsymbol{G}_{m}^{i}, z_{f}^{j} \boldsymbol{A} \rho\left[z_{m}^{j}+z_{f}^{j}\right], \rho \in \mathbf{Q}_{\mathbf{1}} \mathbf{1}
$$

Thus the amount of housing the child consumes is linear in each parent's provision; moreover, the parents' homes are perfect substitutes for the child. These are strong assumptions, but this case provides a benchmark, and allows us to focus on the role of the trade-off between public and private goods in the comparisons below. The decision problems of parents are otherwise as stated above.

Table 1 below summarizes both the choice variables for the parents and the consumption of each of the three agents, in each custodial regime.

\section{Table 1 about here.}

\subsection{A specific example}

For analytical convenience, we adopt Cobb-Douglas utility for all three individuals ${ }^{10}$, and further assume each parent's utility is additively separable in their own consumption and the child's utility. Thus the mother's preferences are given by

${ }^{10}$ While this particular assumption has appealing properties in this case - in particular, some of the child's private good will always be provided by at least one parent - some of the results are sensitive to the functional form. 
$U_{m}=\log x_{m}+\alpha_{m} \log z_{m}+\delta_{m} U_{c}$

while the father's are given by

$$
U_{f}=\log x_{f}+\alpha_{f} \log z_{f}+\delta_{f} U_{c}
$$

The parameter $\delta_{j}, j=m, f$ represents the degree of caring parent $\mathrm{j}$ has towards the child. In general, parents' altruism towards their child is limited, so $\delta_{j} \in(0,1), j=m, f$. The parameter $\alpha_{j}, j=m, f$ represents the relative value parent $\mathrm{j}$ places on (potentially) shared versus private goods in their own utility. Thus $\alpha_{j}>0, j=m, f$.

The (selfish) child has preferences described by

$U_{c}=\log x_{c}+\alpha_{c} \log z_{c}=\log x_{c}+\alpha_{c} \log f\left(z_{m}, z_{c}\right)$

The child in indifferent to the provider of the private goods, so $x_{c}=x_{c m}+x_{c f}$.

The Nash equilibrium values for the six goods chosen by the parents, in both custodial regimes, are displayed in Table 2 below.

\section{Table 2 about here}

Notice that according to the algebra, the amount of the child's private good purchased by either parent could be negative. Simple addition shows that the total private goods consumed by the child is unambiguously positive for any set of parameter values, in either regime; therefore, the algebra does not allow both parents to spend negative amounts on the child. "Negative spending" on the child's private consumption good would take the form of one parent selling the toys, etc, given to the child by the other 
parent; we assume this is never feasible. Moreover, in the main discussion below, we assume all values are strictly positive; we consider the constrained case in appendix 2.

So long as each parent provides strictly positive quantities of the child's private good, the child's consumption of each good is independent of the distribution of family income. This invariance is generated by the public good contribution game: since both parents contribute (by assumption), the amount provided is independent of the distribution of income. An additional dollar of child support transferred from the father to the mother reduces the father's discretionary spending on the child by exactly one dollar in equilibrium. The mother's spending on the child's private good increases by one dollar to compensate - yielding no net change in expenditures. There is an obvious change in the distribution of expenditures: the father's discretionary spending on the child falls, while the mother's rises.

One consequence of this invariance is that the impact of an increase in the custodial parent's income depends on the source of the increase. If the mother's income increases because of a transfer from the father, the child's consumption and utility are unchanged. If, however, the increase comes from outside the family, then spending on all goods consumed by the child increases and the child is better off - as are both parents. An increase in the income of the non-custodial parent has the same effects. 


\section{Comparing sole and joint custody: interior solution}

Under each custodial regime, the distribution of family income will determine the parents' equilibrium expenditures. However, because of the public good contribution game, the consumption of each family member depends only on total family income, in each regime. Thus, it is straightforward to compare the outcomes under the two regimes.

\subsection{Comparative statics}

In both regimes, each parent's spending on the goods they consume depends only on total family income, whereas the amount each spends on the child's private good depends on the family income distribution as well. It is straightforward to show the following comparative static results:

\section{A. Under sole custody:}

i) the more altruistic is the father (the higher is $\delta_{f}$ ): the greater is the mother's spending on her goods at the expense of the child's private good; and the lower is the father's consumption of both goods (since, when the mother has sole custody, there are no goods shared between the father and the child) and the greater is $x_{c f}^{s}$;

ii) the more altruistic is the mother (the higher is $\delta_{m}$ ): the less of her income is spent on her own private consumption and the more on both goods consumed by the child; the greater is the father's own consumption, and hence, the lower his expenditure on the child. 
iii) the greater is the preference of any of the three individuals for housing (that is, the larger is $\alpha_{k}, k=m, f, c$ ): the larger will be the mother's expenditure on housing and the smaller her private consumption; the effect on the child's private good is ambiguous.

iv) an increase in $\alpha_{f}$ results in the father shifting expenditures towards housing, away from both the other goods he purchases, whereas an increase in either $\alpha_{c}$ or $\alpha_{m}$ induces the father to shift purchasing power towards the child's private good.

v) the parents jointly purchase more of the child's private good the more altruistic either is, and the lower the benefit from housing to any of the three family members.

\section{B. Under joint custody:}

i) so long as each parent provides strictly positive quantities of the child's private good, the child's consumption of each good is independent of the distribution of family income.

ii) increased parental altruism shifts expenditures away from housing and towards the child's private good. How this reallocation is accomplished depends on the relative values of the parents' preference parameters.

\subsection{Comparison of utilities across regimes}


Notice first that the share of family income spent on each broad category of goods - private goods for each individual, and housing - is the same across the custodial regimes. However, the utility received from a given aggregate quantity of housing depends on its distribution across households. Since this differs with custody, each individual's consumption bundle differs between regimes - so, therefore, do utilities.

A straightforward comparison shows that $z_{m}^{s}>z_{m}^{j}$ : the mother's expenditure on the good shared with the child falls when the father also shares with the child. The father's expenditure on housing increases when the provision of this good is also for the child: $z_{f}^{j}>z_{f}^{s}$. Since family expenditure on the child's private good is constant, this implies that for any given distribution of family income the mother spends more on the child's private good, and the father less, under joint custody than under sole custody. These results are intuitive, and provide some support for the framework of this paper.

Consider now the distribution of utilities under the two regimes. The explicit expressions for the utilities are given in the appendix. Comparison of the child's utility is straightforward. The child consumes the same quantity of the private good under both regimes; although the amount purchased by each parent differs, since the child does not care who purchases the good, this is irrelevant. The child's consumption of the public good, however, will differ across regimes. Recall that the total quantity of housing purchased is invariant to custody. Under sole custody, the child consumes that housing provided by the custodial parent; if the adults' preferences are identical, the custodial parent will choose more living space than will the non-custodial parent. Under joint custody, the same physical quantities of housing are chosen as in the other regime, but 
these are redistributed between the parents: the mother chooses less, and the father more, than when the child always resides with the mother. While the amount of space available to the child is larger under joint custody, it is not obvious that the utility the child derives from housing increases, since $z_{c}^{s}=z_{m}^{s}$ and $z_{c}^{j}=\rho\left(z_{m}^{j}+z_{f}^{j}\right)$. If $\rho$ is close to unity, the child prefers joint custody. Thus, the easier it is for the child to switch between parents (the larger is $\rho$ ), the more likely it is that the child prefers joint custody.

The utilities of the parents are less straightforward to compare; the results of the comparisons are:

i) If the child's utility is sufficiently different under sole and joint custody, each family member is better off under the custodial regime the child prefers. If the absolute value of the difference in child's utility between the two regimes is not sufficiently large, the parents' rankings of the regimes do not coincide.

ii) Suppose the mother has sole custody. Then, if joint custody would increase (lower) the child's utility, the utility of the father (mother) would also be higher (lower) under joint custody.

iii) Suppose the mother has sole custody, and the child is indifferent between joint and sole custody. Then a move from sole to joint custody increases the utility of the father, at the expense of the mother.

These results depend to some extent on the functional form assumed for preferences, as well as that for the child's housing consumption. Bearance (1999) shows that under different assumptions on preferences, joint custody can improve the welfare of both 
parents while decreasing the utility of the child. The trade-off between family members is important in any assessment of the relative merits of the custodial regimes.

\subsection{Corner solutions}

The comparisons above hold when both parents contribute to the child's private good. There are at least two reasons why this may not be true. First, the division of family income in the first stage may not allow both parents to contribute. Given the assumed preferences, each parent's desired spending on the child's private good is proportional to their own income; moreover, each parent must have a sufficiently high share of total income in order to contribute to the child's private good. Second, additional realism would be achieved by incorporating "lumpy" housing: that is, each parent may need to spend some minimal amount on the shared good, and total family income may not be sufficient to allow this and the other desired expenditures. Since our focus here is how choices depend on the income distribution, we address only the first possibility.

Formally analysing the constrained case requires reformulating the parents' problems allowing explicitly for kuhn-tucker conditions. However, the intuition is straightforward. Consider first the case when the mother's share of total family income $\left(Y_{m} / Y_{T}\right)$ is sufficiently high that the father's spending on the child's private good is forced to its lower bound of zero. ${ }^{11}$ The non-custodial parent would like to reduce the quantity of the child's private good: that is, from the father's perspective the mother is "overspending" on the child. A dollar transferred from the non-custodial to the custodial

${ }^{11}$ Recall we forbid negative expenditures. 
parent would increase the spending on the child by the latter without decreasing that of the former. Similarly, when the mother's income is low enough that the constraint $x_{c m} \leq 0$ binds, then she perceives the father as overspending on the child's private good. Here the same transfer would lead to increased spending on all goods purchased by the mother, thus a decrease in spending on the child's private good.

\section{Policy implications: taxation of child support}

We argued above that the effect on the welfare effects of a change in distribution of income within the family depended upon whether or not both were contributing directly to the child's consumption. In this section, we illustrate this in a discussion of a recent Canadian policy change.

Amendments to the Canadian Federal Divorce Act changed the taxation of support payments made under the act. ${ }^{12}$ Prior to this change, payers of support payments could deduct them from income; support payments were then taxable as income for the custodial parent. Under the current regime, the tax system is effectively blind to support payments: the payer cannot claim them as deductions, and the recipient need not declare support payments as income. Since the custodial parent's income is typically lower than the payer's, and marginal tax rates are increasing, under the current regime less income is available for spending in divorced families.

12 The Divorce Act was amended by Bill C-41, which received royal assent in 1997 and came into effect in May of that year. 
Some people argued that this change was unambiguously bad for divorced couples, and their children, since less income available meant that at least one, and probably all, of the parties would be worse off - including the children. The model in this paper suggests that if both parents contributed to the child's private good both before and after the change, all agents would be strictly better off in the initial regime. However, when only the mother purchases the child's private good, both the custodial parent and the child would be strictly better off after the change. The reasoning is obvious: under sole custody, when the father spends nothing directly on the child, any change in the child's utility depends solely on the income available to the mother. Removing the tax on received support payments leaves more of the family income in the hands of the mother, increasing her utility as well as the child's.

This holds even if the tax switch is accompanied by a reduction in support payments, to (partially) compensate the non-custodial parent for the higher tax burden. So long as the mother's after tax income is higher than when she was liable for the taxes on this portion of family income, both mother and child are better off in the new regime than in the old. (Of course, the non-custodial parent is strictly worse off.)

\section{Conclusions and extensions}

In this paper, we begin a comparison of sole and joint custody. Under the assumption that divorced parents cannot effectively monitor but can reliably predict each other's spending, we characterize the allocation of family income on goods for both the parents and a child as the outcome of a simultaneous Nash game. We distinguish 
between private and public goods for each individual, with "public goods" being those shared by individuals living in the same household; the example we use is housing, which a custodial parent shares with the child. Under each regime, for certain distributions of family income, there is a unique Nash equilibrium outcome, which is invariant to some redistribution between the parents. We derive conditions under which each individual will be better off under sole or joint custody. While all individuals may agree on which regime is better, there exist circumstances when the parents will disagree.

Explicit results in this paper relied on Cobb-Douglas preferences. Adopting other functional forms will alter some of the results, but the invariance result will remain so long as both parents contribute to both goods consumed by the child. One significant assumption is that, for a custodial parent, the amount of "shared goods" provided for the child does not affect the family income. If we interpret shared goods more broadly, and consider time spent with the child as well as housing, this assumption is invalid, since this would reduce time spent in the labor force or at leisure. ${ }^{13}$ How this affects the ranking of sole versus joint custody is beyond this paper.

Given the rankings of sole versus joint custody for both parents and the child, we can now step back and determine which custodial regime might be chosen upon divorce, given parental incomes and various welfare functions. We have established that these rankings will be dependent on the particular preferences of the individuals involved, and that there may be disagreements between the principals. In the case of disagreements, the

${ }^{13}$ See Kennedy and Welling (1997) for an analysis of parental childcare. 
relative weights given to the preferences of the child and each of the parents will determine which regime is "better"; there may well be no universal best scheme. 


\section{APPENDIX 1}

Boundaries for interior and corner solutions:

\section{Sole custody}

$x_{c m}^{s} \geq 0$ iff $\frac{Y_{m}}{Y_{T}} \geq \frac{\delta_{f}\left(1+\alpha_{m}+\alpha_{c} \delta_{m}\right)}{k}$, where $Y_{T}$ is total family income. Similarly,

$x_{c f}^{s} \geq 0$ iff $\frac{Y_{m}}{Y_{T}} \leq \frac{\delta_{f}\left(1+\delta_{m}+\alpha_{m}+\alpha_{c} \delta_{m}\right)}{k}$. These two inequalities create the range of

values for which all the choice variables satisfy the first order conditions of the parents' problems as strict equalities. This range is clearly non-empty so long as both parents care about the child's utility - that is, so long as $\delta_{j}>0, j=m, f$. For values of $Y_{m}$ outside this range, a change in the distribution of income between parents will affect the child's consumption.

\section{Joint custody}

Both parents will choose to purchase private goods for the child so long as the mother's share of total family income falls within the range

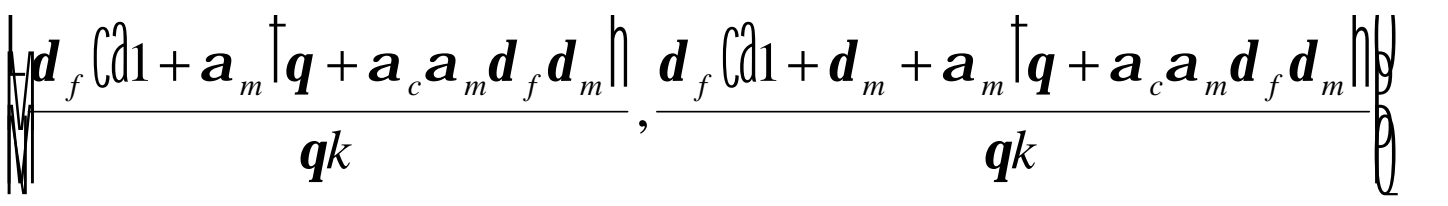

Thus the results above will hold over a range equal to $\frac{\delta_{f} \delta_{m}}{k}$ of total income. The interior solutions are more likely to be relevant the smaller is the weight any individual 
assigns to housing, and the more altruistic is either parent: that is, the more important the child's consumption of private goods is to either parent..

\section{Comparison of sole and joint custody}

Child: under sole custody, the child attains utility equal to

$$
U_{c}^{s}=\log x_{c}^{s}+\alpha_{c} \log z_{m}^{s}=\log \left(\frac{\delta_{m} \delta_{f} Y_{T}}{k}\right)+\alpha_{c} \log \left(\frac{\left(\alpha_{m}+\alpha_{c} \delta_{m}\right) \delta_{f} Y_{T}}{p k}\right)
$$

under joint custody, the child's utility is

$U_{c}^{j}=\log x_{c}^{j}+\alpha_{c} \log \rho\left(z_{m}^{j}+z_{f}^{j}\right)=\log \left(\frac{\delta_{m} \delta_{f} Y_{T}}{k}\right)+\alpha_{c} \log \left(\frac{\rho\left(\theta+\alpha_{c} \delta_{m} \delta_{f}\right) Y_{T}}{p k}\right)$

Mother: When she has sole custody, her utility is

$$
\begin{aligned}
U_{m}^{s}= & \log x_{m}^{s}+\alpha_{m} \log z_{m}^{s}+\delta_{m} U_{c}^{s} \\
& =\log \left(\frac{\delta_{f} Y_{T}}{k}\right)+\alpha_{m} \log \frac{\left(\alpha_{m}+\alpha_{c} \delta_{m}\right) \delta_{f} Y_{T}}{p k}+ \\
& \delta_{m}\left[\log \left(\frac{\delta_{m} \delta_{f} Y_{T}}{k}\right)+\alpha_{c} \log \left(\frac{\left(\alpha_{m}+\alpha_{c} \delta_{m}\right) \delta_{f} Y_{T}}{p k}\right)\right]
\end{aligned}
$$

whereas under joint custody, the mother attains

$$
U_{m}^{j}=\log x_{m}^{j}+\alpha_{m} \log z_{m}^{j}+\delta_{m} U_{c}^{j}
$$




$$
\begin{aligned}
=\log \frac{\delta_{f} Y_{T}}{k}+\alpha_{m} \log \frac{\alpha_{m} \delta_{f}\left(\theta+\alpha_{c} \delta_{m} \delta_{f}\right) Y_{T}}{\theta p k} \\
+\delta_{m}\left[\log \left(\frac{\delta_{m} \delta_{f} Y_{T}}{k}\right)+\alpha_{c} \log \left(\frac{\rho\left(\theta+\alpha_{c} \delta_{m} \delta_{f}\right) Y_{T}}{p k}\right)\right]
\end{aligned}
$$

Father: under sole custody (for the mother), the father attains utility of

$$
\begin{aligned}
U_{f}^{s} & =\log x_{f}^{s}+\alpha_{f} \log z_{f}^{s}+\delta_{f} \log U_{c}^{s} \\
& =\log \frac{\delta_{m} Y_{T}}{k}+\alpha_{f} \log \frac{\delta_{m} Y_{T}}{p k} \\
& +\delta_{f}\left[\log \left(\frac{\delta_{m} \delta_{f} Y_{T}}{k}\right)+\alpha_{c} \log \left(\frac{\left(\alpha_{m}+\alpha_{c} \delta_{m}\right) \delta_{f} Y_{T}}{p k}\right)\right]
\end{aligned}
$$

Under joint custody he obtains

$$
\begin{aligned}
U_{f}^{j}= & \log x_{f}^{j}+\alpha_{f} \log z_{f}^{j}+\delta_{f} \log U_{c}^{j} \\
& =\log \frac{\delta_{m} Y_{T}}{k}+\alpha_{f} \log \frac{\alpha_{f} \delta_{m}\left(\theta+\alpha_{c} \delta_{m} \delta_{f}\right) Y_{T}}{\theta p k} \\
& +\delta_{f}\left[\log \left(\frac{\delta_{m} \delta_{f} Y_{T}}{k}\right)+\alpha_{c} \log \left(\frac{\rho\left(\theta+\alpha_{c} \delta_{m} \delta_{f}\right) Y_{T}}{p k}\right)\right]
\end{aligned}
$$




\section{REFERENCES}

Andreoni, J., 1990. "Impure Altruism and Donations to Public Goods: a Theory of Warm-Glow Giving", Economic Journal, 100, 464-77.

Aiyagari, S.R., J. Greenwood and N. Guner, 2000 "On the State of the Union", Journal of Political Economy, 108,213-44.

Bearance, Marci, 1999, "An economic model of joint custody", MA extended essay, Department of Economics, University of Victoria.

Bergstrom, T., L. Blume and H. Varian, 1986. "On the private provision of public goods", Journal of Public Economics, 29, 25-49.

Brinig, Margaret F. and F.H. Buckley. 1997. “Joint Custody: Bonding and Monitoring Theories". 73 Indiana Law Journal R 3.

Del Boca, Daniela and Christopher Flinn, 1994. "Expenditure Decisions of Divorced Mothers and Income Composition",.The Journal of Human Resources, vol 29, number 3, $742-760$. . 1995. "Rationalizing Child-Support Decisions".

The American Economic Review 85(5):1241-62 .

Folbre, Nancy, 1994, Who pays for the kids? Gender and the structures of constraint. New York: Routledge Press. 
Kanbur, Ravi, 1995. "Children and Intra-Household Inequality: a Theoretical Analysis", in K. Basu, P. Pattanaik, and K. Suzumura (eds) Choice, Welfare, and Development: $a$ festchrift in honour of Amartya Sen, pp.242-252. New York: Oxford University Press.

Kennedy, Peter W. and Linda Welling (1997) "Production Externalities and the Efficiency of Parental Childcare Choices", Canadian Journal of Economics, 30, 822-34.

Lazear, Edward and Robert T. Michael. 1988. Allocation of Income Within the

Household. Chicago: University of Chicago Press.

Lundberg, Shelley and Robert A. Pollak. 1994. "Noncooperative Bargaining Models of Marriage”. AEA Papers and Proceedings 84(2):132-137.

Lundberg, Shelley and Robert A. Pollak. 1993. "Separate Spheres Bargaining and the Marriage Market”. .Journal of Political Economy 101(6):988-1010.

Lundberg, S., R.A. Pollak and T.J. Wales (1997), "Do Husbands and Wives Pool their Resources? Evidence from U.K. Child Benefit", Journal of Human Resources, 32, 463 480.

Phipps, Shelley A. and Peter S. Burton, (1992), What's Mine is Yours? The Influence of Male and Female Incomes on Patterns of Household Expenditure", WP 92-12, Department of Economics, Dalhousie University; forthcoming in Economica. 1995. “Social/Institutional Variables and Behavior within Households: An Empirical Test Using the Luxmbourg Income Study". Feminist Economics 1(1):151-174. 
Warr, P., 1983, "The Private Provision of a Public Good is Independent of the

Distribution of Income", Economics Letters, 13, 207-211.

Weiss, Yoram. 1992. “The Formation and Dissolution of Families: Why Marry? Who Marries Whom? And What Happens Upon Marriage and Divorce". Discussion Paper from Population Research Center, August 1992.

and R. Willis (1985), "Children as Collective Goods", Journal of Labor

Economics, 3: 268-292. 
Table 1: Goods, purchasers, and consumers:

\begin{tabular}{|l|l|l|l|l|}
\hline \multicolumn{1}{|c|}{ Sole custody } & & \\
Consumer & & & & \\
& Mother & Father & Mother & Father \\
\hline Mother & $x_{m}, z_{m}$ & & $x_{m}, z_{m}$ & \\
\hline Father & & $x_{f}, z_{f}$ & & $x_{f}, z_{f}$ \\
\hline Child & $x_{c m}, z_{m}$ & $x_{c f}$ & $x_{c m}, z_{m}$ & $x_{c f}, z_{f}$ \\
\hline
\end{tabular}

The first subscript denotes the consumer; the second, the purchaser (if different) 
Table 2: Nash equilibrium expenditures and consumption: interior solution

\begin{tabular}{|c|c|c|c|c|}
\hline \multicolumn{3}{|c|}{ Sole custody } & \multicolumn{2}{|l|}{ Joint custody } \\
\hline Consumer & Mother & Father & Mother & Father \\
\hline Mother & $\begin{aligned} x_{m}^{s} & =\delta_{f} Y_{s}, \\
z_{m}^{s} & =\left(\alpha_{m}+\alpha_{c} \delta_{m}\right) \delta_{f} Y_{s} / p\end{aligned}$ & & $\begin{array}{l}x_{m}^{j}=\delta_{f} Y_{s} \\
z_{m}^{j}=\alpha_{m} \delta_{f(}\left(\theta+\alpha_{c} \delta_{m} \delta_{f}\right) Y_{s} /(\theta p)\end{array}$ & \\
\hline Father & & $\begin{aligned} x_{f}^{s} & =\delta_{m} Y_{s} \\
z_{f}^{s} & =\alpha_{f} \delta_{m} Y_{s} / p\end{aligned}$ & & $\begin{array}{l}x_{f}^{j}=\delta_{m} Y_{s} \\
z_{f}^{j}=\alpha_{f} \delta_{m}\left(\theta+\alpha_{c} \delta_{m} \delta_{f}\right) Y_{s} /(\theta p)\end{array}$ \\
\hline Child & $\begin{array}{l}x_{c m}^{s}=\left[\left(1+\alpha_{f}+\delta_{f}\right) \delta_{m} Y_{m}\right. \\
-\left(1+\alpha_{m}+\alpha_{c} \delta_{m}\right) \delta_{f} Y / k \\
z_{m}^{s}\end{array}$ & $\begin{aligned} x_{c f}^{s}= & {\left[\left(1+\alpha_{m}+\delta_{m}\left(1+\alpha_{c}\right)\right) \delta_{f}\right.} \\
& \left.-\left(1+\alpha_{f}\right) \delta_{m} Y_{m}\right] / k\end{aligned}$ & $\begin{array}{l}x_{c m}^{j}=\left[\left(\theta+\alpha_{c} \alpha_{f} \delta_{m} \delta_{f}\right)\left(\delta_{m} Y_{m}-\delta_{f} Y_{f}\right)\right. \\
+\theta\left(\left(\delta_{f}+\alpha_{f}\right) \delta_{m} Y_{m}\right. \\
\left.\left.-\alpha_{m} \delta_{f} Y_{f}\right)\right] /(\theta k) \\
z_{m}^{j}\end{array}$ & $\begin{array}{l}x_{c m}^{j}=\left[\left(\theta+\alpha_{c} \alpha_{f} \delta_{m} \delta_{f}\right)\left(\delta_{f} Y_{f}-\delta_{m} Y_{m}\right)\right. \\
+\theta\left(\left(\delta_{f}+\alpha_{f}\right)\right) \delta_{f} Y_{f} \\
\left.-\alpha_{f} \delta_{m} Y_{m}\right] /(\theta k) \\
z_{f}^{j}\end{array}$ \\
\hline
\end{tabular}

The first subscript denotes the consumer; the second, the purchaser (if different); superscripts denote the custodial regime: $j=j o i n t, s=s o l e$

$$
\begin{aligned}
& Y_{s}=\left(Y_{m}+Y_{f}\right) / k \\
& k \equiv \delta_{m}\left(1+\alpha_{f}\right)+\delta_{f}\left(1+\delta_{m}\right)+\delta_{m} \delta_{f}\left(1+\alpha_{c}\right), \quad \theta \equiv \alpha_{m} \delta_{f}+\alpha_{f} \delta_{m}
\end{aligned}
$$

